American Medical Journal 3 (2): 82-92, 2012

ISSN 1949-0070

(C) 2012 Science Publications

\title{
Sex, Health Behaviors and Social Support: Functional Decline among Older Diabetics
}

\author{
Emily Joy Nicklett \\ School of Social Work, University of Michigan, \\ 1080 South University Avenue, 3772, Ann Arbor, MI 48109
}

\begin{abstract}
Problem statement: Men and women experience pronounced differences in functional decline as they age. The mechanisms behind these differences remain unclear, particularly among chronically ill populations. Drawing on the theory of the disablement process, this research examines sex differences in functional decline, focusing on two mechanisms suggested by the literature to partially mediate these disparities: health behaviors and social support. Approach: Data from diabetics aged 50 and older from the Health and Retirement Study $(n=2,493)$ were examined for change in functional status over a 10-year period. Multivariate longitudinal multi-level models were conducted to analyze (1) health behavior (2) social support; and (3) a full model with health behavior and social support together, followed by a separate analysis using sex interaction terms. Results: Women and men both experienced functional decline over time. In the models that examined health behaviors and social support separately, women experienced steeper rates of decline. In the full model (which included health behaviors and social support together), men experienced a steeper rate of decline relative to women. The analyses suggest that it is the combination of health and social characteristics (largely through engagement in socially supportive activities that promote health) that are protective against functional decline. Conclusion/Recommendations: As diabetic men experienced a steeper rate of functional decline than diabetic women once health behaviors and social support were both held constant, future research must examine (a) how these protective factors operate in tandem to protect against disablement of women with diabetes; and (b) how clinical and social policy can promote multipronged interventions to improve health behaviors in supportive contexts. Such research will benefit from multi-disciplinary collaborations.
\end{abstract}

Key words: Sex/gender, diabetes, functional status, older adults, risk/protective factors

\section{INTRODUCTION}

For decades, researchers have investigated sex differences in health (Enterline, 1961; Madigan, 1957; Nathanson, 1977; Verbrugge, 1975). However, men and women are exposed to different health threats over the life course. This study investigates sex differences in long-term functional status among adults with diabetes in middle age and later life. Although studies have consistently found that women have higher rates of functional decline than men, the mechanisms underlying differential rates of decline are not clear. Drawing from disablement theory, this study tests two common explanations for differences in functional decline by sex relevant to chronically ill populations: health behavior and support.

In general, studies have found higher rates of mortality among men and higher rates of disability among women (Gorman and Read, 2006; Newman and Brach, 2001; Wingard et al., 1989; Verbrugge, 1985). In a comparative study, women reported more functional limitations in all age categories, reporting 2.3 Activity of Daily Living (ADL) and Instrumental Activity of Daily Living (IADL) limitations, compared to 1.6 limitations for men (Spitze and Logan, 1989). Further, approximately $23 \%$ of women (age-adjusted) reported ADL limitations and $31 \%$ of women reported IADL limitations, compared to 17 and $15 \%$ for men respectively (Spitze and Logan, 1989). This gap also increases with age, even in the elderly years (Gorman and Read, 2006; Liang et al., 2008; Marks, 1996; Newman and Branch, 2001).

Men have higher levels of life-threatening chronic diseases and mortality and have lower levels of nonthreatening chronic disease morbidity than women. This population trend is described by Verbrugge and Wingard (1987) as the "iceberg of morbidity". Less is known, however, about sex differences in disability among populations who are already chronically ill. In this limited research, one study focusing on health decline among type 2 diabetics aged 60 and older found 
no significant sex differences in the probability of health status decline after controlling for illness support, health behaviors and other disease and socioeconomic factors (Nicklett and Liang, 2010).

Previous research suggests that men and women experience pronounced differences in functional status and that these differences grow as populations age (Gorman and Read, 2006). The mechanisms, however, are not well understood; sex disparities in health and functional outcomes are difficult to capture because risk exposure varies by kind of risk, subgroup and stage of the life course. Social disadvantage could relate to functional outcomes for men and women differently, which could lead to contradictory research findings. Sex differences in functional status and other health outcomes are a product of differential gendered exposure to health insults over time. The advantage of this study is that differences in exposures to risk and protective factors will be examined over a 10-year period, which enables explanatory, dependent and control measures to vary over time.

The previous studies introduce several challenges for research: many studies do not take differential mortality into consideration, as men are more likely to die from a chronic illness than are women (Verbrugge, 1985). Further, most studies are cross-sectional and therefore are not able to prospectively examine long-term outcomes. While it has been established that functional decline is much more rapid among chronically ill populations such as diabetics (Wu et al., 2003), little is known about why men and women differ in these processes.

The present study addresses this gap by examining longitudinal sex differences in the mechanisms related to functional decline of diabetics over time. This study focuses on the diabetic population due to the rapid increase in diabetes incidence and prevalence. Among older adults, diabetes contributes to more rapid rates of physical disability over time (Gregg et al., 2000). Diabetes is projected to grow in age-adjusted prevalence 2.2 times among those aged 65-74 years and 4.5 times among those 75 years and above (Narayan $e t$ al., 2006). Further, diabetes is a chronic illness with a complex regimen, requiring extensive self-care. Diabetics can benefit from different forms of social support (e.g., instrumental or emotional), leading to divergent outcomes. This research addresses gendered aspects of self-care and social support among older diabetics. This study is unique in that the examined mechanisms will vary over time (using random slope, random intercept longitudinal multi-level models). This method allows for an enhanced analysis by establishing temporal precedence between predictors and outcome variables-ensuring appropriate temporal ordering through analysis of time-varying covariates.

\section{Review of mechanisms}

Health behaviors: In general, men and women are exposed to risk factors differently, with men engaging in more risk-inducing and less health-promoting behavior than women (Courtenay, 2000; Goldberg, 1976; Gochman, 1988; Waldron, 1976), which challenges the "surviving myth of masculine privilege" in health (Verbrugge, 1985). This is a particular concern for chronically ill populations. Sex differences in health behaviors can complicate the analysis. For example, health promotion behaviors could be adopted in response to a life-threatening disease or as a chronic illness regimen. The temporal ordering of this relationship could be missed by cross-sectional research due to lack of specification of the time order of the key variables. Further, many longitudinal studies lack the complexity in the survey design to disentangle changing health behaviors and risk factors of the respondents over time. The majority of variables used in this analysis are time-varying, allowing changes over time to be observed in the prediction of longitudinal disability outcomes.

Health behaviors are dynamically different between men and women. While most studies have found that men are more physically active than women (Dean, 1989), womens' exercise patterns are more health-promoting and sustainable relative to those of men (Dean, 1989; Walker et al., 1988; Weissfeld et al., 1990). Although women have historically had more problems with being overweight and obese, men use alcohol and tobacco more frequently than women and at younger ages (Dean, 1989; Harrell et al., 1998; Kann et al., 1998; Pascale and Evans, 1993; Kessler et al., 1994; Robins et al., 1984). Substance use is associated with a higher prevalence. Sex differences in substance use, diet and different kinds of physical activity-all strongly linked to the onset and control of chronic illnesses such as diabetes-could explain the high mortality rates among men, particularly those with chronic disease (Galuska $e t$ al., 1996).

Women and men also differ in health care utilization, with men generally utilizing fewer health services (Courtenay, 2000). Although women are more likely to seek preventative care, extensive research has documented sex disparities in the care that men and women receive. For example, physician screening and treatment practices for chronic illnesses are more rigorous for men in clinical settings, particularly for cardiovascular disease and diabetes (Bird et al., 2007; Correa-de-Araujo et al., 2006; Rathore et al., 2001; Wexler et al., 2005). 
Social support: The benefit of social relationships for health has long been recognized in the literature and there is compelling evidence that this can be extended to chronically ill populations (Glass et al., 2000; Schulz et al., 2006; Uchino, 2004; Baum et al., 2009). Community and population-based studies of chronically ill older adults have found social support to be protective against mortality, health/functional decline and cognitive decline (Berkman and Breslow, 1983; Eng et al., 2002; Seeman, 1996; Seeman et al., 2001). Unfortunately, it is difficult to disentangle the relative effects of social support, networks and social ties (Berkman et al., 2000), which are often used interchangeably in the literature. Marriage and family are positively associated with health, largely due to the avoidance of negative health behaviors and the adoption of positive health behaviors-particularly for men (Schoene and Weinick, 1998; Umberson, 1987).

In addition to general social support, social ties can be beneficial to chronically ill individuals. Social ties are activated to share health-related information (Kang et al., 1994; Marshall et al., 1995), to handle feelings associated with chronic illnesses (Roberts et al., 1994; Spiegel et al., 1989) and to promote illness selfmanagement (Gallant, 2003; Nicklett and Liang, 2010). Studies have found that those with higher levels of social support are more likely to modify unhealthy behavior (Gruninger, 1995), to adhere to medical treatment (Meichenbaum and Turk, 1987; O'Brien et al., 1992) and to engage in positive healthier behaviors and practices overall (Bovbjerg et al., 1995; Cwikel et al., 1988; Lonnquist et al., 1992; Schoene and Weinick, 1998), with some exceptions (Nicklett et al., 2012).

Despite the benefits of social ties, social relationships can also bring responsibility and strain, which is unequally distributed in society by race/ethnicity and by and socioeconomic status or class (Weiss et al., 2005; Pirraglia et al., 2005; Savage and Bailey, 2004). This is particularly salient through the extensive process of providing informal care to relatives with chronic illnesses such as diabetes (Langa et al., 2002). In addition to the continuing need of care, the burden of caregiving continues to fall on women, despite their disproportionate burden of disability over the life course. Based on theory and previous research, three hypotheses are tested in this analysis among diabetic older adults.

Hypothesis 1: Women will experience steeper rates of functional decline than men.

Hypothesis 2: (a) Health behaviors that are beneficial will be negatively associated with functional decline over time for both men and women while risky health behaviors will be positively associated with functional decline over time for both men and women; (b) Women will engage in more beneficial health behaviors-and in fewer less risky health behaviors-relative to men.

Hypothesis 3: The receipt of social support is negatively associated with functional decline over time.

These hypotheses concern the relationship between sex and functional decline among diabetic older adults. Further, these hypotheses address the roles of health behaviors and social support in this process. This study examines whether or not differences in sex, health behaviors and social support influence the progression of functional decline over time. As theorized by Verbrugge and Jette (1994), disablement is not a uniform process. Initial risk factors influence the speed and experience of the disablement process, leading to impairments in body systems (including chronic conditions such as diabetes). Verbrugge and Jette (1994) further argue that the process leads to heterogeneous outcomes in functional limitations and disability, which can be mediated by "extraindividual factors" (such as external supports, care available and the social environment) and "intraindividual factors" (including lifestyle changes and psychosocial aspects). This study examines the extent to which risk factors (sex), extra-individual factors (social support) and intra-individuals factors (health behaviors consistent with a diabetes regimen) speed or slow the process of functional decline among diabetics over a 10year period.

\section{MATERIALS AND METHODS}

In the present study, quantitative data are used to analyze differences by sex in functional status and the role of mediating factors (health behaviors and social support) in narrowing or widening these sex disparities over time. Here, we briefly discuss the sample and methodological procedures for the study.

Sample: To examine the hypotheses, 10 years of longitudinal data are examined. Data were drawn from the Health and Retirement Study (HRS) using the RAND (1994) combined data files and imputations. HRS is a national, population-based study that has tracked individuals and households since 1992. Data were also used from the 2003 HRS Diabetes Supplement, which was fielded to 2,391 cases who (a) reported having diabetes in HRS 2002 and (b) were eligible for supplemental examination. Surveys were returned by 1,901-approximately $80 \%$ of the eligible pool. The mailed survey requested diabetes-specific information and had more general questions regarding health, illness and utilization of care. The data are linked to the larger HRS sample with person-level identifiers. The HRS and the 2003 Diabetes Supplement studies are conducted by the University of Michigan. 
The analytic sample consisted of 2,493 adults aged 50-103 who (a.) participated in the 1998 HRS wave and in at least 2 follow up waves; and (b.) either reported having type 2 diabetes at baseline or reported developing type 2 diabetes during the 10-year followup observation period (1998-2008). Respondents were included in the sample even if they did not participate in the 2003 HRS Diabetes Supplement, but they had item-missing data on those variables. Observations are in person-year format in longitudinal multi-level analyses. While the analytic sample includes 2,492 respondents, respondents participated in up to 6 biennial waves, resulting in cross-wave 18,572 pooled observations.

Measures: The dependent variable throughout this analysis is a time-varying measure of functional status. Functional status was constructed by combining the number of ADL and IADL activities respondents report having had any difficulty in performing in each of the 6 waves. ADL and IADL measures have been traditionally combined to provide an improved range and sensitivity of measurement of functional disability among older adults (Spector and Fleishman, 1998). Functional status therefore refers to limitations in performing living tasks (including basic personal care activities) and other activities, referred to as ADLs and IADLs, respectively. Following RAND (1994), cross-wave ADLs include difficulty walking across a room, getting in and out of bed, dressing, bathing and eating. Further, IADLs include using the phone, managing money and taking medications. These ADLs and IADLs were selected because they were consistently measured in each of the study waves. The year-varying values range from 0-8 $(0$ $=$ no difficulty performing any tasks and $8=$ at least some difficulty in performing all tasks). Change in functional status is indicated as a statistically significant value that is either positive (suggesting functional decline over a 10-year period) or negative (suggesting functional improvement over a 10 -year period).

Sex is a dichotomous time invariant measure. The explanatory measures of health behavior were selected based upon previous literature relevant to diabetics and functional status for both men and women (and were limited based on availability of the data). The measures of health behavior include: (a.) number of doctors visits in the last 2 years (time-varying and top-coded at 52 visits over a period of 2 years); (b.) whether or not the respondent receives home health care (time-varying); (c.) degree satisfaction with provider management of care ("Overall, what grade would you give your doctors, nurses, or other health care providers for how well they helped you manage your diabetes in the past six months? A+ - F), from the 2003 Diabetes Survey (time-invariant); (d.) a categorical weight level variable constructed according to BMI thresholds, including underweight, right weight, overweight and obese (timevarying); (e.) whether or not they currently smoke (time-varying); (f.) currently drink alcohol (timevarying); and (g.) currently engage in physical activity 2-3 days or more per week (time-varying).

The explanatory social support measures were selected to capture different aspects of social support (emotional, support, tangible support, social ties, provision of care) that have been found to be protective against decline for both men and women in previous literature. Measures of social support include: (a.) whether or not the respondent is currently married or partnered (time-varying); (b.) a dichotomous variable indicating whether or not the respondent received informal care for diabetes. This variable was operationalized by asking whether or not the respondent identified a spouse, other family member, or friend (in contrast to a paid caregiver or nobody) as handling most of their diabetes care on their response to the 2003 Diabetes Survey (time-invariant); (c.) a composite scale (1-40) variable measuring the extent to which the respondent reported they could rely on family or friends to provide disease-related support on a variety of adherence dimensions, based on their responses to the 2003 Diabetes Survey (time-invariant); (d.) a measure of physical ability relative to one's spouse, which is a categorical variable comparing the respondent's ADL/IADL levels to those of one's spouse or partner, if applicable, indicating if they are better, worse, or the same (time-varying); and (e.) categorical variables of the number of family members still living (timevarying), including parents (0-2), siblings $(0-4+)$ and children (0-4+).

Covariates were chosen that relate to health outcomes among chronically ill older adult populations and that might also contribute to sex difference in health. Covariates included (a.) self-reported race/ethnicity (white, black, Latino and other) and (b.) highest level of education achieved (less than high school, high school/GED, some college and college or more), which were both time-invariant. Additional control variables include (c.) whether or not the respondent was currently working for pay, part-or fulltime (time-varying), (d.) household assets (minus debts) per year (time-varying); (e.) the number of chronic conditions, including high blood pressure, cancer, lung disease, heart disease, stroke, psychiatric problems and arthritis (time-varying), (f.) The age at baseline (time invariant), depression as measure by the Center for Epidemiological Studies Depression (CESD) scale (timevarying) and (g.) the year the respondent reported they were diagnosed with diabetes (time invariant). RAND imputed missing income data (RAND, 1994) and adjusted for slight variations in questions across the waves. 
Am. Med.J. 3 (2): 82-92, 2012

Table 1: Functional Status and Gender Interactions (1998-2008): Health and Social Ties

\begin{tabular}{|c|c|c|c|c|c|c|c|c|c|c|c|c|c|c|c|c|}
\hline & \multicolumn{5}{|c|}{ Model 1 (Health) } & \multicolumn{5}{|c|}{ Model 2 (Social Ties) } & \multicolumn{6}{|c|}{ Model 3 (Full Model) } \\
\hline & \multicolumn{2}{|l|}{ Pooled } & & \multicolumn{2}{|c|}{ Interaction } & \multicolumn{2}{|l|}{ Pooled } & & \multicolumn{2}{|c|}{ Interaction } & \multicolumn{2}{|l|}{ Pooled } & & \multicolumn{3}{|c|}{ Interaction } \\
\hline & Coeff & $\mathrm{P}>|\mathrm{z}|$ & & Coeff & $\mathrm{P}>|\mathrm{z}|$ & Coeff & $\mathrm{P}>|\mathrm{z}|$ & & Coeff & $\mathrm{P}>|\mathrm{z}|$ & Coeff & $\mathrm{P}>|\mathrm{z}|$ & & Coeff & $\mathrm{P}>|\mathrm{z}|$ & \\
\hline cons & 12.913 & 0.004 & *** & 0.000 & 0.000 & 16.721 & 0.001 & **** & & & 13.137 & 0.005 & *** & & & \\
\hline Year $^{\dagger}$ & 0.334 & 0.217 & & 0.000 & 0.000 & 0.360 & 0.185 & & & & 0.294 & 0.220 & & & & \\
\hline Year squared $^{\dagger}$ & -0.099 & 0.122 & & 0.000 & 0.000 & -0.113 & 0.084 & * & & & -0.075 & 0.193 & & & & \\
\hline \multicolumn{17}{|l|}{ Race/Ethnicity (white ref) } \\
\hline Black & 0.222 & 0.001 & $* * *$ & -0.066 & 0.552 & 0.062 & 0.430 & & -0.009 & 0.938 & 0.011 & 0.890 & & 0.060 & 0.602 & \\
\hline Hispanic & 0.273 & 0.003 & $* *$ & -0.177 & 0.221 & 0.135 & 0.161 & & 0.034 & 0.828 & 0.150 & 0.121 & & 0.029 & 0.848 & \\
\hline Other & 0.087 & 0.649 & & 0.084 & 0.774 & -0.171 & 0.395 & & 0.323 & 0.280 & -0.082 & 0.679 & & 0.213 & 0.462 & \\
\hline \multicolumn{17}{|l|}{ Education (HS ref) } \\
\hline Less than High School & 0.031 & 0.651 & & 0.048 & 0.641 & 0.041 & 0.582 & & 0.094 & 0.412 & 0.010 & 0.897 & & 0.098 & 0.370 & \\
\hline Some College & -0.066 & 0.423 & & 0.025 & 0.829 & -0.004 & 0.961 & & 0.075 & 0.549 & -0.075 & 0.397 & & 0.105 & 0.384 & \\
\hline College or More & -0.060 & 0.563 & & 0.079 & 0.549 & -0.059 & 0.592 & & 0.121 & 0.391 & -0.028 & 0.794 & & 0.102 & 0.451 & \\
\hline Working Status (ref: work) & )$^{\dagger} \quad 0.232$ & 0.000 & $* * *$ & 0.114 & 0.111 & 0.207 & 0.000 & $* * *$ & 0.110 & 0.093 & 0.233 & 0.000 & $* * * *$ & 0.142 & 0.046 & $*$ \\
\hline Mean Hhd Assets ${ }^{\dagger}$ & 0.000 & 0.079 & $*$ & 0.000 & 0.277 & 0.000 & 0.077 & * & 0.000 & 0.296 & 0.000 & 0.361 & & 0.000 & 0.720 & \\
\hline Age at BL (above 0) & -0.006 & 0.100 & & 0.011 & 0.041 & ** $\quad-0.010$ & 0.020 & *** & 0.005 & 0.443 & -0.013 & 0.003 & *** & 0.009 & 0.146 & \\
\hline C-ESD & 0.100 & 0.000 & $* * *$ & 0.003 & 0.810 & 0.081 & 0.000 & $* * *$ & -0.029 & 0.029 & 0.081 & 0.000 & $* * * *$ & -0.038 & 0.009 & $* *$ \\
\hline Comorbidities ${ }^{\dagger}$ & 0.194 & 0.000 & $* * *$ & -0.039 & 0.161 & 0.177 & 0.000 & $* * *$ & -0.043 & 0.090 & 0.127 & 0.000 & $* * *$ & -0.015 & 0.584 & \\
\hline Year Diagnosed & -0.007 & 0.002 & $* *$ & 0.000 & 0.569 & -0.008 & 0.001 & $* * *$ & 0.000 & 0.795 & -0.006 & 0.007 & $* *$ & 0.000 & 0.546 & \\
\hline Doc Visits in last $2 \mathrm{Yrs}^{\dagger}$ & 0.004 & 0.003 & ** & 0.000 & 0.891 & & & & & & 0.004 & 0.003 & $* *$ & -0.001 & 0.458 & \\
\hline Home care (ref: receiving) & 0.509 & 0.000 & $* * *$ & -0.016 & 0.851 & & & & & & 0.416 & 0.000 & $* * *$ & -0.029 & 0.739 & \\
\hline Rate Doc's Performance & 0.003 & 0.812 & & 0.017 & 0.379 & & & & & & 0.015 & 0.314 & & 0.032 & 0.127 & \\
\hline \multicolumn{17}{|l|}{ Weight Level (ref: Right) ${ }^{\dagger}$} \\
\hline Underweight & -0.025 & 0.912 & & -0.117 & 0.800 & & & & & & -0.131 & 0.566 & & 0.239 & 0.650 & \\
\hline Overweight & -0.086 & 0.912 & & -0.043 & 0.622 & & & & & & -0.093 & 0.131 & & -0.025 & 0.778 & \\
\hline Obese & 0.221 & 0.008 & $* *$ & -0.252 & 0.094 & $*$ & & & & & 0.151 & 0.075 & & -0.259 & 0.088 & $*$ \\
\hline Smoke (ref: smoke) ${ }^{\dagger}$ & 0.242 & 0.001 & $* * *$ & 0.372 & 0.000 & $* * *$ & & & & & 0.175 & 0.022 & $* *$ & 0.247 & 0.020 & $* *$ \\
\hline Currently Drinking (ref: yes & es) ${ }^{\dagger} 0.111$ & 0.024 & ** & 0.006 & 0.931 & & & & & & 0.102 & 0.048 & $* *$ & -0.010 & 0.877 & \\
\hline Vigorous Phys. Act (ref: ye & es) ${ }^{\dagger}-0.123$ & 0.004 & $* *$ & 0.053 & 0.357 & & & & & & -0.061 & 0.168 & & 0.038 & 0.506 & \\
\hline Partnership (ref: marr/part) & & & & & & -0.609 & 0.000 & $* * *$ & -0.475 & 0.012 & -0.729 & 0.000 & $* * *$ & -0.626 & 0.001 & $* * *$ \\
\hline Informal Care (ref: rec. 200 & & & & & & 0.145 & 0.028 & $* *$ & -0.065 & 0.563 & 0.044 & 0.497 & & 0.019 & 0.860 & \\
\hline Support for Adherence (200 & 03 ) & & & & & -0.003 & 0.523 & & 0.004 & 0.533 & 0.004 & 0.353 & & 0.001 & 0.873 & \\
\hline Comp. Partner (ref: same) ${ }^{\dagger}$ & & & & & & & & & 0.057 & 0.150 & & & & 0.075 & 0.093 & $*$ \\
\hline Better & & & & & & -0.841 & 0.000 & $* * *$ & & & -0.797 & 0.000 & $* * *$ & & & \\
\hline Worse & & & & & & -0.822 & 0.000 & $* * *$ & & & -0.816 & 0.000 & $* * *$ & & & \\
\hline Living Family ${ }^{\dagger}$ & & & & & & & & & -0.090 & 0.255 & & & & -0.074 & 0.374 & \\
\hline \multicolumn{17}{|l|}{ Parents (ref: 2) } \\
\hline 0 & & & & & & -0.212 & 0.172 & & & & -0.121 & 0.450 & & & & \\
\hline 1 & & & & & & -0.128 & 0.365 & & & & -0.061 & 0.672 & & & & \\
\hline Siblings (ref: 0$)^{\dagger}$ & & & & & & & & & -0.017 & 0.539 & & & & -0.025 & 0.370 & \\
\hline 1 & & & & & & -0.131 & 0.022 & $* *$ & & & -0.144 & 0.015 & $* *$ & & & \\
\hline 2 & & & & & & -0.167 & 0.011 & ** & & & -0.127 & 0.059 & $*$ & & & \\
\hline 3 & & & & & & -0.186 & 0.013 & $* *$ & & & -0.148 & 0.057 & $*$ & & & \\
\hline $4+$ & & & & & & -0.118 & 0.142 & & & & -0.045 & 0.585 & & & & \\
\hline Children (ref: 0$)^{\dagger}$ & & & & & & & & & 0.046 & 0.173 & & & & 0.044 & 0.183 & \\
\hline 1 & & & & & & 0.069 & 0.539 & & & & 0.115 & 0.303 & & & & \\
\hline 2 & & & & & & 0.150 & 0.164 & & & & 0.133 & 0.209 & & & & \\
\hline 3 & & & & & & 0.068 & 0.558 & & & & 0.049 & 0.670 & & & & \\
\hline $4+$ & & & & & & 0.087 & 0.467 & & & & 0.098 & 0.410 & & & & \\
\hline Log Likelihood & -7314.000 & & & & & -7361.000 & & & & & -5570.000 & & & & & \\
\hline Level 1, Level 2 Units & 5565.000 & 1441.000 & & & & 5952.000 & 1223.000 & & & & 4618.000 & 000.1178 & & & & \\
\hline Variance at Level 1,2 & 0.587 & 1.661 & & & & 0.492 & 1.436 & & & & 0.466 & 1.091 & & & & \\
\hline Covariance and Cor $(2,1)$ & -0.337 & -1.000 & & & & -0.235 & -0.946 & & & & -0.250 & -0.838 & & & & \\
\hline $\operatorname{var}(2)$ & 0.079 & & & & & 0.043 & & & & & 0.082 & & & & & \\
\hline
\end{tabular}

Significance Levels: $\mathrm{p}<.001(* * *), \mathrm{p}<.05(* *), \mathrm{p}<.01\left(^{*}\right) ; \dagger$; Indicates varies over the year

Analytic strategy: A series of statistical procedures were used to test the hypotheses concerning functional status, sex, health behaviors and social support over time. The hypotheses were tested through a series of Maximum Likelihood Estimation (MLE) multivariable regression models with random slopes and random intercepts. The hypotheses were tested with three sexpooled models to examine individual predictors for longitudinal health decline (regardless of sex) and whether or not these remained consistent controlling for health and/or social characteristics. In the examination of the disablement process, this step analyzed the contribution of extra-individual factors (social support) and intra-individual factors (health behaviors relevant to a diabetes regimen) on change in functional decline. The hypotheses were also tested with a series of analyses using sex interaction terms to test for significance in sex differences for each predictor over time, or how risk factors, extra-individual factors and intra-individual factors could speed or slow functional decline. The hypotheses are not competing and therefore could act in conjunction with one another. Therefore, the models examining sex and the interaction terms contribute greatly to this analysis.

Random intercept, random slope regression models tested the hypothesis in an iterative two-stage formulation. The reduced-form level-1 and level-2 models are as follows:

$$
\begin{aligned}
& \mathrm{yij}=\gamma_{11}+\gamma_{21} \mathrm{xij}+\beta_{3} \mathrm{x} 2 \mathrm{ij}+\gamma_{12} \mathrm{wj}+\zeta_{1 j}+\zeta_{2 j} \mathrm{x} 2 \mathrm{ij}-\epsilon \mathrm{ij} \\
& \mathrm{yij} \equiv \beta_{1}+\beta_{2} \mathrm{xij}+\beta_{3} \mathrm{x} 2 \mathrm{ij}+\beta_{4 \mathrm{wj}}+\zeta_{1 j}+\zeta_{2 \mathrm{x}} \mathrm{ij}-\epsilon \mathrm{ij}
\end{aligned}
$$


where $y_{i j}$ is the functional status of the adult $j$ at the given wave $\mathrm{i}$ ' $\mathrm{x}_{\mathrm{ij}}$ is the corresponding year $(1992=0)$ and certain covariates are covariates only in the intercept equation $\left(\mathrm{w}_{\mathrm{j}}\right)$ representing time-varying covariates in this analysis). As shown in the model above, the intercept and the slope $\left(\beta+\zeta_{2 j}\right)$ vary by time (year squared) $\left(\mathrm{x}_{2 \mathrm{ij}}\right)$ and other respondents (j) (Raudenbush and Bryk, 2002; Rabe-Hesketh and Skrondral, 2012).

An important feature of these models is the assumption that the intercept $\left(\zeta_{1 \mathrm{j}}\right)$ and slope $\left(\zeta_{2 \mathrm{j}}\right)$ parameters vary across individuals (and interact with time as a person-year), so that they become dependent variation in the level two (or person-level) model, where individual characteristics are included as predictors. This is an appropriate strategy as functional status is associated with a decline among older adults and observations are therefore not independent from responses in previous waves. This model also uses all available data for respondents (j) and study waves (i) where neither the response $\mathrm{y}_{\mathrm{ij}}$ nor the covariates $\mathrm{x}_{\mathrm{ij}}$ are missing. Longitudinal multi-level models enable individuals to be followed over time who have unequal numbers of measurements or who are present at different time periods in a longitudinal study: all observations are used that are available for a given respondent in the analysis (West et al., 2007). This strategy has benefits over other longitudinal data approaches that remove subjects based on missing data (Rabe-Hesketh and Skrondral, 2012). The model assumes a normal distribution with an unstructured covariance matrix and that data are missing at random. Different variables had relatively low correlations (all under 0.3). All variables were missing less than $20 \%$ of data during waves in which participants were eligible to be part of the analytic sample. The degree to which data were missing was not significantly predicted by sex or functional limitations. The final model was rerun using multiple imputations for item missing data; however the results did not differ significantly from those presented. All analyses were conducted using Stata.

The first analysis included a pooled longitudinal analysis of sex, health behavior and covariates as predictors of functional decline. A second analysis included a sex interaction term. Social support measures were excluded. Model 2 included the social support variables and excluded the health behavior characteristics. Model 3 included the health behavior variables, the social support variables, as well as the covariates to examine the hypothesis with the mechanisms tested and modeled with the other key variables. These results are presented in Table 1.

\section{RESULTS}

Model 1: In the initial model, diabetic women experienced shaper rates of functional decline compared to men. Model 2: When the model controlled for social support (but not health behaviors), the differences between diabetic men and women in functional decline became even more pronounced, suggesting that health characteristics and particularly social support were more beneficial for diabetic men than for women. Model 3: The full model suggests that diabetic men experienced a much steeper rate of functional decline than did women, controlling for both health behaviors and social support. When the sex interaction term was added to the analysis, being male was significantly $(\mathrm{p}<0.001)$ associated with functional decline, a reverse in direction from the relationship in Model 1 . These findings suggest that while individually, health behaviors and social support were more beneficial to men, together, health and social support interacted to have protective effects against functional decline, particularly for women, over time.

This study examined the relationships between sex, health behavior and social support as predictors of functional decline among middle and old age diabetics. The measures in this analysis did not uniformly operate for men and women and between the separate models and the full models, suggesting that mechanisms conventionally understood to exacerbate health disparities between men and women are indeed situational and population-specific. These findings offer support to the disablement framework, suggesting that initial risk factors (sex) iteratively and dynamically lead to functional limitations over time for diabetic populations. Further, inter- and extra- individual characteristics not only influence the disablement process, but also interact with one another to affect long-term disability. As discussed previously, in aggregate, functional decline was significantly sharper for women in Models 1-2, which offers support to the first hypothesis. However, after controlling for health behaviors and social support in conjunction, men are shown to have a significantly steeper rate of functional decline relative to women, which challenges the first hypothesis. The sex differences in the roles of health behaviors and social support for functional decline will be discussed here.

\section{DISCUSSION}

Health behaviors such as not smoking, drinking less alcohol and to some extent, engaging in physical activity were protective against health decline for both 
men and women with diabetes. Despite the findings that women did generally engage in healthier (and in fewer riskier) behaviors than men, the sex differences in functional decline widened after health behaviors were included in the model. Controlling for health behaviors exacerbated the differences between men and women in functional status decline. When social support measures were included in the model, however, the effect and significance of health behaviors generally decreased. Smoking was more strongly associated with functional decline among diabetic men than women (which could be attributed to a longer duration of smoking status among men). Obesity was particularly strongly associated with functional decline for diabetic women. The significance of the long-term outcomes of these health behaviors is weakened in the full model.

Being in a marriage/partnership was significantly protective against functional decline for diabetic men, which was further strengthened when the health characteristics were included in the final model. In this analysis, marriage/partnership is protective for women in the sample, but the magnitude differs according to health behaviors. The strong support found for interactions with health behaviors relates to previous literature finding marriage beneficial for both men and women due to better accumulated health behaviors over the life course (Schoene and Weinick, 1998; Waite, 1995).

Some research suggests that providing informal care invokes strains, particularly when the caregiver is a spouse (Spitze and Logan, 1989; Noelker and Wallace, 1985; Sherman et al., 1988). Other research has addressed more positive aspects of caregiving (Braithwaite, 2000; Charmaz, 1993). This study could offer support to both: Having a spouse with a different functional status than one's own was protective further research is needed that examines relationships between partners who both face a combination of chronic illness, health decline, disability (and gendered effects of marriage at different life stages). Much can be learned from additional qualitative research to tailor interventions focusing on family units and resources in their social environments.

This study is limited to diabetics in mid- and later life and is not generalizable to the rest of the population: while individuals must have been well enough to survive the initial data collection, diabetics are generally worse in health and lower in socioeconomic status than are non-diabetics in the U.S. Further, the functional decline of diabetics is more rapid than the average population (Wu et al., 2003). The applicability of these findings to other chronic illnesses is not known and warrants further study. As with more longitudinal studies of older adults, subject mortality could bias the results. The longitudinal multilevel model does not take subject mortality into consideration (respondents are not dropped from the analysis if they experience attrition through nonresponse or mortality). Respondents who died during the study period were significantly more likely to be male compared to those who remained alive during the entire study period. However, the sex distribution of mortality in the sample did not differ significantly from that among the HRS sample in the corresponding age group and time period.

This study uses only one dimension of healthfunctional decline-measured through the change in the presence or absence of functional limitations. As an overall concept, health is more appropriately conceptualized as an interplay of overall physical, psychological and social well-being. However, functional status was chosen as it is accurately reported by men and women and is appropriate to measure over time (Macintyre et al., 1999; Merrill et al., 1997).

As with most social and epidemiological studies based on survey data, there could be problems related to omitted variable bias. Other factors not examined here include biological factors, different occupational and environmental exposures factors and differential exposure to life events (Thoits, 1987; Kessler, 1979; Kessler and McLeod, 1984). Additional factors include economic and job-related pressures (Wheaton, 1990; McLeod, 1984; Eckenrode and Gore, 1990) and other aspects of chronic stress, which may be experienced and embodied differently by gender (Springer et al., 2012; Slepian et al., 2011; Horowitz et al., 1996; Umberson et al., 1996). Despite the care taken to take temporal precedence into account, the quantitative model was not able to parse out the directionality of within-year (simultaneous) observations. In addition, several measures are time-invariant due to data limitations (such as informal care and social support) which limit the ability to analyze the relationship between these factors and outcomes over time by biological sex.

The differences between functional limitations and disability have been noted in the literature, with the latter referring to "the loss or reduction of the ability to perform expected or specific social role activities of extended duration because of a chronic disease or impairment" (Levine et al., 1990). Simply put, disability is the examination of functional limitations within a person's social or environmental context, often requiring behavior to be altered (Sussman, 1966; Pope and Tarlov, 1991). Further qualitative research is needed to gain a more textured analysis of how sex, health behaviors and social ties fit and interact in this process of transition. 


\section{CONCLUSION}

Conclusions and implications: The influence of sex on functional decline differs greatly by social support and health behaviors. Specifically, more research is needed that addresses how social support matters for functional decline differently by gender, level of obesity, and co morbidity. As Christakis and Fowler (2007) suggest, social networks can have a powerful impact on health behaviors and, hence, on obesity.

This study found that social support interacted with health characteristics to predict functional decline. As little research has examined both social and healthrelated factors as mechanisms for long-term outcomes between men and women, future work is needed that qualitatively examines these relationships and explores these relationships in greater depth, preferably to additional populations. In addition, the results show strong interactive relationships between sex, social support, health factors and subsequent disability. Future research should be centered around gendered notions of how support and social relationships relate to illness and health. Such studies must address how different forms of support operate as sex-specific mediators. Such research is a precursor to identifying gender- and socially-appropriate interventions for chronically ill populations. Such interventions would involve addressing health problems within social contexts. Practitioners, such as physicians, nurses, dietitians and social workers are ideally positioned to collaborate to establish more effective, crosscutting interventions.

\section{ACKNOWLEDGEMENT}

The researcher is particularly grateful to Professors Sarah Burgard, Renee Anspach, Pamela Smock and Jersey Liang for guidance on this manuscript, as well as to Brady West for extensive statistical support and expertise. The author is also grateful for funding that supported this research from the National Institute on Aging and from the Hartford Foundation for Geriatric Social Work.

\section{REFERENCES}

Baum, A., T. Revenson and J. Singer, 2009. Handbook of Health Psychology. 2nd Edn., Taylor and Francis, ISBN-10: 0805814957, pp: 1000.

Berkman, L.F. and L. Breslow, 1983. Health and Ways of Living: The Alameda County Study. 1st Edn., Oxford University Press, USA., ISBN-10: 0195032160. pp: 237.
Berkman, L.F., T. Glass, I. Brissette and T.E. Seeman, 2000. From social integration to health: Durkheim in the new millennium. Soc. Sci. Med., 51: 843857. DOI: $10.1016 /$ S0277-9536 (00)00065-4

Bird, C.E., A.M. Fremont, A.S. Bierman, S. Wickstrom and M. Shah et al., 2007. Does quality of care for cardiovascular disease and diabetes differ by gender for enrollees in managed care plans? Women's Health Issues, 17: 131-138. DOI: 10.1016/j.whi.2007.03.001 PMID: 17434752

Bovbjerg, V.E., B.S. McCann, D.J. Brief, W.C. Follette and B.M. Retzlaff et al., 1995. Spouse support and long-term adherence to lipid-lowering diets. Am. J. Epidemiol., 141: 451-460.

Braithwaite, V. 2000. Contextual or general stress outcomes making choices through Caregiving appraisals. Gerontologist, 40: 706-717. DOI: 10.1093/geront/40.6.706

Charmaz, K., 1993. Good Days, Bad Days: The Self in Chronic Illness and Time. 1st Edn., Rutgers University Press, New Brunswick, N.J., ISBN-10: 0813519675, pp: 324.

Christakis, N.A. and J.H. Fowler, 2007. The spread of obesity in a large social network over 32 years. N. Eng. J. Med., 357: 370-379. DOI: 10.1056/NEJMsa066082

Correa-De-Araujo, R., B. Stevens, E. Moy, D. Nilasena and F. Chelsey et al., 2006. Gender differences across racial and ethnic groups in the quality of care for acute myocardial infarction and heart failure associated with comorbidities. Women's Health Issues, 16: 44-55. DOI: 10.1016/j.whi.2005.04.003

Courtenay, W.H., 2000. Behavioral factors associated with disease, injury and death among men: Evidence and implications for prevention. J. Men's Stud., 9: 81-142.

Cwikel, J.M., T.E. Dielman, J.P. Kirsch and B.A. Israel, 1988. Mechanisms of psychosocial effects on health: The role of social integration, coping style and health behavior. Health Educ. Q., 15: 151-173. PMID: 3378901

Dean, K., 1989. Self-care components of lifestyles: The importance of gender, attitudes and the social situation. Soc. Sci. Med., 29: 137-152. DOI: 10.1016/0277-9536(89)90162-7

Eckenrode, J. and S. Gore, 1990. Stress Between Work and Family. 1st Edn., Plenum Press, New York, pp: 223.

Eng, P.M., E.B. Rimm, G. Fitzmaurice and I. Kawachi, 2002. Social ties and change in social ties in relation to subsequent total and cause-specific mortality and coronary heart disease incidence in men. Am. J. Epidemiol., 155: 700-709. DOI: 10.1093/aje/155.8.700 
Enterline, P.E., 1961. Causes of death responsible for recent increases in sex mortality differentials in the United States. Milbank Mem. Fund Q., 39: 312328. PMID: 13890360

Gallant, M.P., 2003. The influence of social support on chronic illness self-management: A review and directions for research. Health Educ. Behav., 30: 170-195. DOI: $10.1177 / 1090198102251030$

Galuska, D.A., M. Serdula, E. Pamuk, P.Z. Siegel and T. Byers, 1996. Trends in overweight among US adults from 1987 to 1993: A multistate telephone survey. Am. J. Public Health, 86: 1729-1735. DOI: 10.2105/AJPH.86.12.1729

Glass, T.A., B. Dym, S. Greenberg, D. Rintell and C. Roesch et al., 2000. Psychosocial intervention in stroke: Families in Recovery From Stroke Trial (FIRST). Am. J. Orthopsychia, 70: 169-181. DOI: 10.1037/h0087746

Gochman, D.S., 1988. Health Behavior: Emerging Research Perspectives. 1st Edn., Springer, New York, ISBN-10: 0306428741, pp: 440.

Goldberg, H., 1976. The Hazards of Being Male: Surviving the Myth of Masculine Privilege. 1st Edn., Nash Publishing, Plainview, New York, ISBN-13: 9780840213648 , pp: 200.

Gorman, B.K. and J.G. Read, 2006. Gender disparities in adult health: An examination of three measures of morbidity. J. Health Soc. Behav., 47: 95-110. DOI: $10.1177 / 002214650604700201$

Gregg, E.W., G.L. Beckles, D.F. Williamson, S.G. Leveille and J.A. Langlois et al., 2000. Diabetes and physical disability among older U.S. adults. Diabetes Care, 23: 1272-1277. PMID: 10977018

Gruninger, U.J., 1995. Patient education: An example of one-to-one communication. J. Hum. Hypertens., 9: 15-25. PMID: 7730996

Harrell, J.S., S.I. Bangdiwala, S. Deng, J.P. Webb and C. Bradley, 1998. Smoking initiation in youth. J. Adolesc. Health, 23: 271-279. DOI: 10.1016/S1054-139X(98)00078-0

Horowitz, A.V., H.R. White and S. Howell-White, 1996. The use of multiple outcomes in stress research: A case study of gender differences in responses to marital dissolution. J. Health Soc. Behav., 37: 278-291.

Kang, S.H., J.R. Bloom and P.S. Romano, 1994. Cancer screening among African-American women: Their use of tests and social support. Am. J. Public Health, 84: 101-103. DOI: 10.2105/AJPH.84.1.101

Kessler, R.C. and J.D. McLeod, 1984. Sex differences in vulnerability to undesirable life events. Am. Soc. Rev., 49: 620-631.
Kessler, R.C., 1979. Stress, social status and psychological distress. J. Health Soc. Behav., 20: 259-272. PMID: 479536

Kessler, R.C., K.A. McGonagle, S. Zhao, C.B. Nelson and M. Hughes et al., 1994. Lifetime and 12-month prevalence of DSM-III-R psychiatric disorders in the United States. Results from the National Comorbidity Survey. Arch. Gen. Psychia., 51: 819. PMID: 8279933

Langa, K.M., S. Vijan, R.A. Hayward, M.E. Chernew and C.S. Blaum et al., 2002. Informal Caregiving for diabetes and diabetic complications among elderly Americans. J. Gerontol. B Psychol. Sci. Soc. Sci., 57: S177-S186. DOI: 10.1093/geronb/57.3.S177

Levine, D.B., B.H. Singer and M. Zitter, 1990. Linda Ingram, Disability Statistics: An Assessment. 1st Edn., National Academies, Washington, D.C., pp: 71.

Liang, J., J.M. Bennett, B.A. Shaw, A.R. Quinones and W. Ye et al., 2008. Gender differences in functional status in middle and older age: Are there any age variations? J. Gerontol. B Psychol. Sci. Soc. Sci., 63: S282-S292.

Lonnquist, L.E., G.L. Weiss and D.L. Larsen, 1992. Health value and gender in predicting health protective behavior. Women Health, 19: 69-85. PMID: 1492412

Macintyre, S., G. Ford and K. Hunt, 1999. Do women 'over-report' morbidity? Men's and women's responses to structured prompting on a standard question on long standing illness. Soc. Sci. Med., 48: 89-98. DOI: 10.1016/S0277-9536(98)00292-5

Madigan, F.C., 1957. Are sex mortality differentials biologically caused? Milbank Mem. Fund Q., 35: 202-223.

Marks, N.F., 1996. Socioeconomic status, gender and health at midlife: Evidence from the Wisconsin Longitudinal Study. Res. Sociol. Health Care, 13A: 135-152.

Marshall, A.A., S.W. Smith and J.K. McKeon, 1995. Persuading low-income women to engage in mammography screening: Source, message and channel preferences. Health Commun., 7: 283-299. DOI: $10.1207 / \mathrm{s} 15327027 \mathrm{hc} 0704 \_1$

Meichenbaum, D. and D.C. Turk, 1987. Facilitating Treatment Adherence: A Practitioner's Guidebook. 1st Edn., Plenum Press, New York, ISBN-10: 0306426382, pp: 310.

Merrill, S.S., T.E. Seeman, S.V. Kasl and L.F. Berkman, 1997. Gender differences in the comparison of self-reported disability and performance measures. J. Gerontol. A Biol. Sci. Med. Sci., 52A: M19-M26. DOI: 10.1093/Gerona/52A.1.M19 
Narayan, K.M., J.P. Boyle, L.S. Geiss, J.B. Saaddine and T.J. Thompson, 2006. Impact of recent increase in incidence on future diabetes burden: U.S., 2005-2050. Diabetes Care, 29: 2114-2116. DOI: $10.2337 / \mathrm{dc} 06-1136$

Nathanson, C.A., 1977. Sex, illness and medical care: A review of data, theory and method. Soc. Sci. Med., 11: 13-25. DOI: 10.1016/0037-7856(77)90141-X

Newman, A.B. and J.S. Brach, 2001. Gender gap in longevity and disability in older persons. Epidemiol. Rev., 23: 343-350. DOI: 10.1093/Oxfordjournals.epirev.a000810

Nicklett, E.J. and J. Liang, 2010. Diabetes-related support, regimen adherence and health decline among older adults. J. Gerontol. B Psychol. Sci. Soc. Sci., 65B: 390-399. DOI: 10.1093/geronb/gbp050

Nicklett, E.J., R.D. Semba, E.M. Simonsick, S. Szanton and K. Bandeen-Roche et al., 2012. Diet quality and social support: Factors associated with serum carotenoid concentrations among older disabled women (The Women's Health and Aging Study). J. Nutr. Health Aging, 16: S11-S18. DOI: 10.1007/s12603-012-0031-2

Noelker, L.S. and R.W. Wallace, 1985. The organization of family care for impaired elderly. J. Fam. Issues, 6: 23-44. DOI: 10.1177/019251385006001003

O'Brien, M.K., K. Betrie and J. Raeburn, 1992. Adherence to medication regimens: Updating a complex medical issue. Med. Care Rev., 49: 435454. DOI: $10.1177 / 002570879204900403$

Pascale, P.J. and W.J. Evans, 1993. Gender differences and similarities in patterns of drug use and attitudes of high school students. J. Drug Educ., 23: 105116. DOI: 10.2190/6RCG-PV89-W810-8J01

Pirraglia, P.A., D. Bishop, D.S. Herman, E. Trisvan and R.A. Lopez et al., 2005. Caregiver burden and depression among informal caregivers of HIVinfected individuals. J. Gen. Intern. Med., 20: 510514. DOI: 10.1111/j.1525-1497.2005.0073.x PMID: 15987325

Pope, A.M. and A.R. Tarlov, 1991. Disability in America: Toward a National Agenda for Prevention. 1st Edn., National Academy Press, Washington, D.C., ISBN-10: 0309043786, pp: 362.

Rabe-Hesketh, S. and A. Skrondal, 2012. Multilevel and Longitudinal Modeling using Stata. 3rd Edn., Stata Press, ISBN-10: 159718103X, pp: 514.

RAND, 1994. Center for the study of aging. RAND Corporation.
Rathore, S.S., A.K. Berger, K.P. Weinfurt, 2001. Race, sex, poverty and the medical treatment of acute myocardial infarction in the elderly. ACC Curr. J. Rev., 10: 17-17. DOI: 10.1016/S10621458(00)00166-5

Raudenbush, S.W. and A.S. Bryk, 2002. Hierarchical Linear Models: Applications and Data Analysis Methods. 2nd Edn. Sage Publications, Thousand Oaks, CA., ISBN-10: 076191904X, 485.

Roberts, C.S., C.E. Cox, V.J. Shannon and N.L. Wells, 1994. A closer look at social support as a moderator of stress in breast cancer. Health Soc. Work, 19: 157-164. PMID: 7959397

Robins, L.N., J.E. Helzer, M.M. Weissman, H. Orvaschel and E. Gruenberg et al., 1984. Lifetime prevalence of specific psychiatric disorders in three sites. Arch. Gen. Psychiatry, 41: 949-958. PMID: 6332590

Savage, S. and S. Bailey, 2004. The impact of caring on caregivers' mental health: A review of the literature. Aust. Health Rev., 27: 111-117. PMID: 15362303

Schoene, B.S. and R.M. Weinick, 1998. Health-related behaviors and the benefits of marriage for elderly persons. Gerontologist, 38: 618-627. DOI: 10.1093/geront/38.5.618

Schulz, A.J., B.A. Israel, S.N. Zenk, E.A. Parker and R. Lichtenstein et al., 2006. Psychosocial stress and social support as mediators of relationships between income, length of residence and depressive symptoms among African American women on Detroit's east side. Soc. Sci. Med., 62: 510-522. PMID: 16081196

Seeman, T.E., 1996. Social ties and health: The benefits of social integration. Ann. Epidemiol., 6: 442-451. DOI: 10.1016/S1047-2797(96)00095-6

Seeman, T.E., T.M. Lusignolo, M. Alpert and L. Berkman, 2001. Social relationships, social support and patterns of cognitive aging in healthy, highfunctioning older adults: MacArthur studies of successful aging. Health Psychol., 20: 243-255. DOI: $10.1037 / / 0278-6133.20 .4 .243$

Sherman, S., R. Ward and M. LaGory, 1988. Women as caregivers of the elderly: Instrumental and expressive support. Soc. Work, 33: 164-167.

Slepian, M.L., M. Weisbuch, N.O. Rule and N. Ambady, 2011. Tough and tender: Embodied categorization of gender. Psychol. Sci., 22: 26-28. DOI: $10.1177 / 0956797610390388$

Spector, W.D. and J.A. Fleishman, 1998. Combining activities of daily living with instrumental activities of daily living to measure functional disability. J. Gerontol. B Psychol. Sci. Soc. Sci., 53B: S46-S57. DOI: $10.1093 /$ geronb/53B.1.S46 
Spiegel, D., H.C. Kraemer, J.R. Bloom and E. Gottheil, 1989. Effect of psychosocial treatment on survival of patients with metastatic breast cancer. Lancet, 334: 888-891. DOI: $10.1016 /$ S01406736(89)91551-1

Spitze, G. and J. Logan, 1989. Gender differences in family support: Is there a payoff? Gerontologist, 29: 108-113. DOI: 10.1093/geront/29.1.108

Springer, K.W., J.M. Stellman and R.M. Jordan-Young. 2012. Beyond a catalogue of differences: A theoretical frame and good practice guidelines for researching sex/gender in human health. Soc. Sci. Med., 74 : $18171824 . \quad$ DOI: 10.1016/j.socscimed.2011.05.033

Sussman, M.B., 1966. Sociology and Rehabilitation. 1st Edn., American Sociological Association, Washington, D.C., pp: 265.

Thoits, P.A., 1987. Gender and marital status differences in control and distress: Common stress versus unique stress explanations. J. Health Soc. Behav., 28: 7-22. DOI: 10.2307/2137137

Uchino, B.N., 2004. Social Support and Physical Health: Understanding the Health Consequences of Relationships. 1st Edn., Yale University Press, New Haven, CT, ISBN-10: 0300102186, pp: 222.

Umberson, D., 1987. Family status and health behaviors: Social control as a dimension of social integration. J. Health Soc. Behav., 28: 306-319. DOI: $10.2307 / 2136848$

Umberson, D., M.D. Chen, J.S. House, K. Hopkins and E. Slaten, 1996. The effect of social relationships on psychological well-being: Are men and women really so different? Am. Soc. Rev., 61: 837-857. DOI: $10.2307 / 2096456$

Verbrugge, L.M. and D.L. Wingard, 1987. Sex differentials in health and mortality. Women Health, 12: 103-145. DOI: 10.1300/J013v12n02_07

Verbrugge, L.M. 1975. Morbidity and mortality in the United States: A riddle of the sexes Johns Hopkins University, Baltimore, Maryland.

Verbrugge, L.M. 1985. Gender and health: An update on hypotheses and evidence. J. Health Soc. Behav., 26: 156-182. DOI: $10.2307 / 2136750$

Verbrugge, L.M. and A.M. Jette, 1994. The disablement process. Soc. Sci. Med., 38: 1-14. DOI: 10.1016/0277-9536(94)90294-1
Waite, L.J., 1995. Does marriage matter? Demography, 32: 483-507. DOI: $10.2307 / 2061670$

Waldron, I., 1976. Why do women live longer than men? Soc. Sci. Med., 10: 349-362. DOI: 10.1016/0037-7856(76)90090-1

Walker, S.N., K. Volkan, K.R. Sechrist and N.J. Pender, 1988. Health-promoting life styles of older adults: Comparisons with young and middle-aged adults, correlates and patterns. Adv. Nurs. Sci., 11, 76-90. PMID: 3140723

Weiss, C.O., H.M. Gonzalez, M.U. Kabeto and K.M. Langa, 2005. Differences in amount of informal care received by non-Hispanic whites and Latinos in a nationally representative sample of older Americans. J. Am. Geriatr. Soc., 53: 146-151. DOI: $10.1111 / \mathrm{j} .1532-5415.2005 .53027 . \mathrm{x}$

Weissfeld, J.L., J.P. Kirsch and B.M. Brooke, 1990. Health beliefs in a population: The Michigan blood pressure survey. Health Educ. Q., 17: 141-155. DOI: $10.1177 / 109019819001700202$

West, B.T., K.B. Welch and A.T. Galecki, 2007. Linear Mixed Models: A Practical Guide using Statistical Software. 1st Edn., Chapman and Hall/CRC, Boca Raton, Fla., ISBN-10: 1584884800, pp: 353.

Wexler, D.J., R.W. Grant, J.B. Meigs, D.M. Nathan and E. Cagliero, 2005. Sex disparities in treatment of cardiac risk factors in patients with type 2 diabetes. Diabetes Care, 28: 514-520. DOI: 10.2337/diacare.28.3.514

Wheaton, B., 1990. Life transitions, role histories and mental health. Am. Soc. Rev., 55: 209-223. DOI: $10.2307 / 2095627$

Wingard, D.L., B.A. Cohn, G.A. Kaplan, P.M. Cirillo and R.D. Cohen, 1989. Sex differentials in morbidity and mortality risks examined by age and cause in the same cohort. Am. J. Epidemiol., 130: 601-610. PMID: 2764004

Wu, J.H., M.N. Haan, J. Liang, D. Ghosh and H.M. Gonzalez et al., 2003. Diabetes as a predictor of change in functional status among older Mexican Americans: A population-based cohort study. Diabetes Care, 26: 314-319. DOI: 10.2337/diacare.26.2.314 